\title{
Fixation of sulphur in the gut by bismuth salts
}

\author{
J. T. WRIGHT AND J. GUPTE
}

From the Medical Research Laboratories, London Hospital

EDITORIAL SYNOPSIS This study arose from an observation 50 years ago that the dark colour of the stools during the administration of bismuth salts was due to bismuth sulphide, and provides quantitative data on sulphur fixation by bismuth salts. Whether the fixation of sulphur has a therapeutic advantage has yet to be studied.

Dyspepsia is one of the commonest afflictions of civilized man; Doll, Avery Jones, and Buckatzsch (1951) found that it occurred at least in mild form in approximately $30 \%$ of a largely industrial population, although in only about $5 \%$ was it attributed to peptic ulcer.

Widely different views are held in different parts of the world regarding the causes of dyspepsia unrelated to ulcer and in the majority of cases treatment must be empirical. For many years antacid preparations containing bismuth salts have been used in the treatment of these conditions.

The cost of bismuth and its use in military materials led to its omission from the Formulary during the Second World War; after the war its reappraisal as an antacid (Alstead, 1954) ensured its continued rejection from the National Formulary.

Therapeutic fashions change rapidly, but a 200 year-old tradition dies hard and although the prescription of bismuth salts for gastrointestinal disorders is officially discouraged it is not proscribed and many patients seem still to have a preference for proprietary remedies containing bismuth. It may be simply that patients like the taste of bismuth (Druitt, 1862). The suggestion that bismuth salts form a protective coat on ulcers was advanced long ago (Caley, 1905) but is still unproven. The observation that bismuth salts inhibit pepsin (Bateson, 1954 ) is also worthy of further study.

We have been interested in another old observation (Caley, 1905) that the dark colour of the stools during administration of bismuth salts is due to bismuth sulphide and that the presumed fixation of irritant hydrogen sulphide gas may be of therapeutic value. The object of our investigation has been to acquire quantitative data on sulphur fixation without necessarily confirming that this phenomenon is therapeutically beneficial.

\section{CLINICAL DATA}

We obtained the cooperation of two normal subjects and seven convalescent patients, all of whom, with two exceptions, were eupeptic. We also made random observations on the stools of a number of other patients. With one exception, a vegetarian, suffering from a duodenal ulcer, the subjects were on a normal type of diet of sulphur content varying between 600 and $1,000 \mathrm{mg}$./day. Bismuth carbonate was given in varying dosage for varying periods in each case after a preliminary period of stool collection during which all medicaments were withheld.

Details of the methods used for stool collection and analysis are given in the Appendix.

\section{RESULTS}

It was found that much inorganic sulphide disappeared from the stools on drying and the method used for analysis (see Appendix) was therefore devised to estimate total sulphide in the fresh specimen and the portion remaining 'fixed' after drying.

Table I shows that the inorganic sulphur content of stools of subjects on established bismuth therapy is much higher than before administration of bismuth began.

\section{TABLE I}

FAECAL SULPHIDE CONTENT UNDER NORMAL CONDITIONS AND DURING ESTABLISHED ADMINISTRATION OF BISMUTH CARBONATE

\begin{tabular}{lll} 
& Total $S$ ( $\mu$ g./g.) & 'Fixed' $S(\mu g . / g)$. \\
Normal conditions (34 specimens) & \\
\hline Mean & $25 \cdot 4 \pm 5 \cdot 3$ & $2 \cdot 1$ \\
Range & $3-113$ & $0-14$
\end{tabular}

During established administration of bismuth carbonate (37 specimens)

$\begin{array}{lrl}\text { Mean } & 251 & 167 \\ \text { Range } & 80-620 & 18-384\end{array}$ 

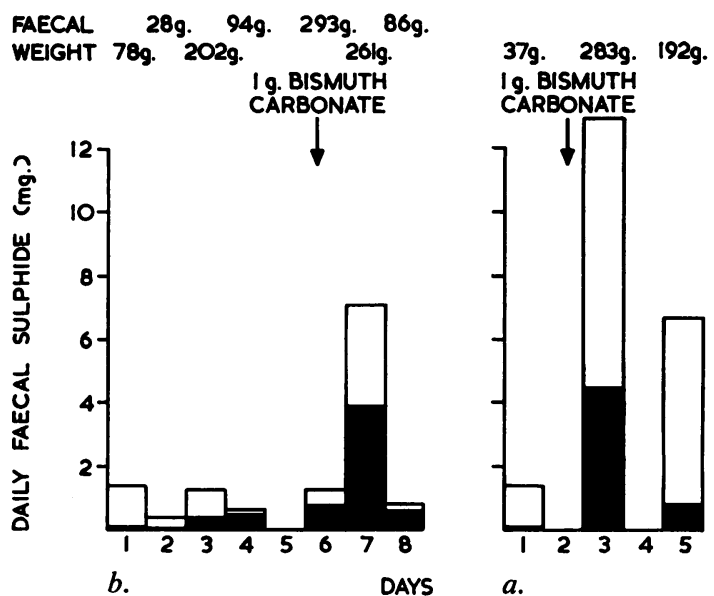

FIG. 1. The effect in two normal subjects of a single dose of bismuth carbonate on faecal sulphide content.

In the one subject whose vegetarian diet contained lower than 'normal' amounts of sulphur, we found negligible quantities of sulphide in the stool examined before bismuth administration, but high concentrations $(510 \mu \mathrm{g} . / \mathrm{g}$. and $470 \mu \mathrm{g}$. $/ \mathrm{g}$. $)$ in specimens of stools examined one week and two weeks after taking bismuth carbonate 2 g. t.d.s.

Figure 1 shows the effect in two patients of a single dose of $1 \mathrm{~g}$. bismuth carbonate. In each case the rise in faecal sulphide output is of the order of seven times the pre- 'treatment' level. In case $a$ an increase in sulphide output could be interpreted simply in terms of a seven-fold increase in weight of the stool passed on the day after the bismuth as compared with the day before. In case $b$, however, the preliminary stools analysis period is longer and it will be seen that the total sulphur output for stools weighing 78, 202, and $293 \mathrm{~g}$. respectively is virtually the same and yet the day after bismuth there was a seven-fold increase in sulphur with a stool weight of only $261 \mathrm{~g}$.

Figure 2 shows the effect of continuous administration of bismuth carbonate, $3 \mathrm{~g}$. daily, to a subject $c$ suffering from diarrhoea of unknown cause. The first effect of the bismuth appears to be a sharp rise in stool weight as well as sulphur content on the day after therapy began, followed by a two-day period of constipation and then recurrence of diarrhoea with enormously increased sulphide output.

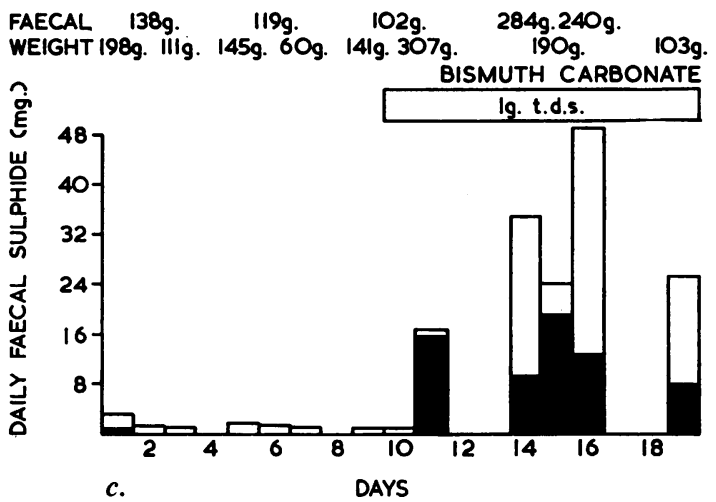

Fig. 2. The effect of continued administration of bismuth carbonate on faecal sulphide content. The patient was under investigation for unexplained diarrhoea.

Figure 3 shows the effect in two subjects of a 10fold increase in the dose of bismuth after a week on the normal dose. In neither case did the stool sulphide content rise further; on the contrary, towards the end of the period of observation there was a drop in faecal sulphide, which in the case of subject $d$ was most remarkable in the 'fixed' sulphur.

Figure 4 shows the effect of simultaneous administration of Neomycin and bismuth carbonate. Both

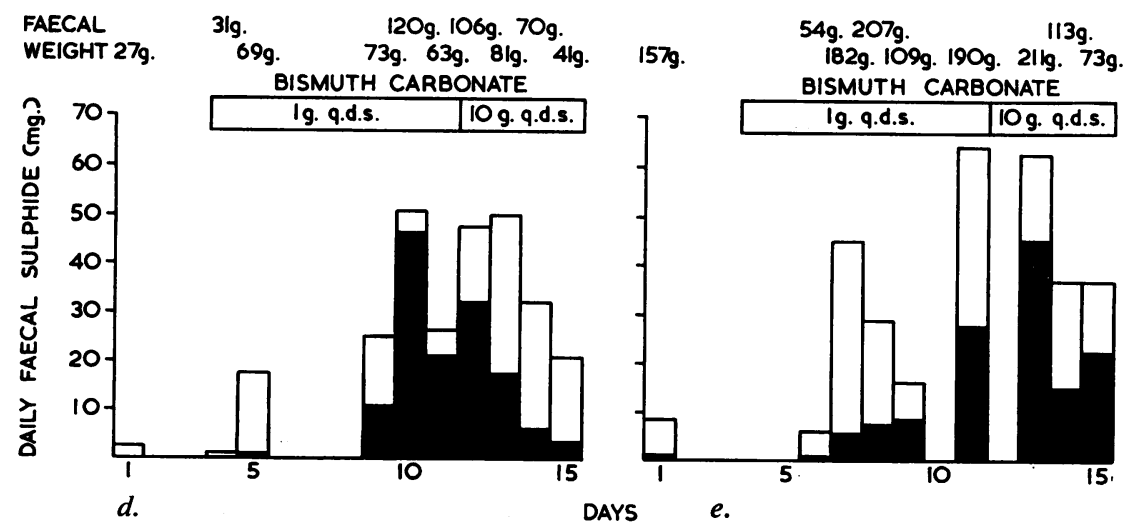

FIG. 3. The effect in two normal subjects of a tenfold increase in dose of bismuth carbonate on faecal sulphide content. 


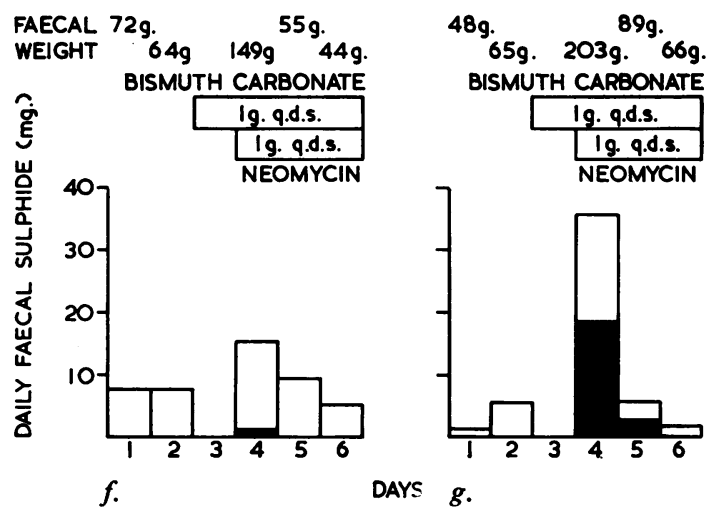

FIG. 4. The effect in two normal subjects of concurrent administration of Neomycin and bismuth carbonate on faecal sulphide content.

subjects show a rise in faecal sulphide after starting bismuth and a rapid return to normal faecal levels the day after Neomycin administration began. The changes are less convincing in the case of subject $f$, but there was some evidence that he did not take his full dose of bismuth.

One subject, $h$, received bismuth carbonate $6 \mathrm{~g}$. daily for a week, followed after a two-day interval by aluminium hydroxide, $\mathbf{3} \mathbf{g}$. daily for four days, and then after a further two-day interval a similar dosage of a powder containing equal parts pulv. mag. carb. $\mathrm{Co}$ and calcium carbonate for four days. This régime covered a three-week period during which regular bowel habits remained undisturbed and it was felt reasonable to confine analysis to the days on which a particular 'therapeutic' régime began or ended. The results, shown in Fig. 5, are expressed in terms of sulphide content per gram of faeces and show that only during bismuth administration does this rise.

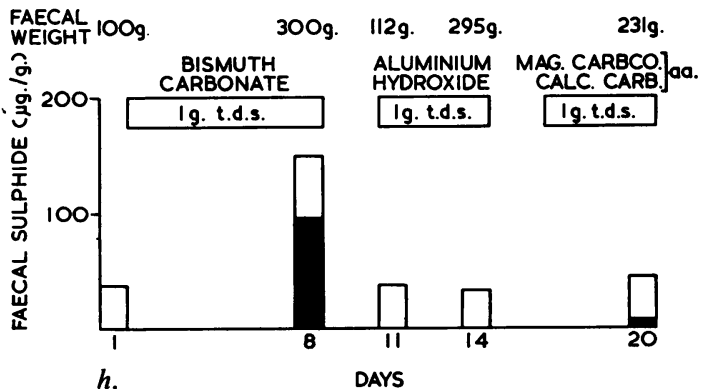

FIG. 5. The effect in a normal subject of bismuth carbonate, aluminium hydroxide, and mag. carb. Co and calcium carbonate on faecal sulphide. Only stools passed at the beginning and end of each period of 'treatment' were assayed, the result being given in $\mu \mathrm{g} . / \mathrm{g}$. of faeces (wet weight).
Administration of iron salts leads to darkening of the faeces and observations of a similar nature to those described in Fig. 5 were made on subject $j$. The results (Fig. 6) show sulphide concentrations of the same order as those in bismuth administration. By the same token it was felt that some of the dark colour in melaena stools might be due to iron sulphide and Table II does indeed show higher than

TABLE II

SULPHIDE CONTENT OF MELAENA STOOLS

\begin{tabular}{|c|c|c|}
\hline Subject & Total S ( $\mu \mathrm{g} . / \mathrm{g})$. & 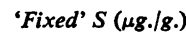 \\
\hline $\mathbf{k}$ & $53 \cdot 6$ & 17.9 \\
\hline 1 & $45 \cdot 2$ & 4.8 \\
\hline $\mathrm{m}$ & $52 \cdot 6$ & 4.4 \\
\hline $\mathrm{n}$ & 189 & $\mathbf{0}$ \\
\hline
\end{tabular}

average sulphide content in four melaena stools from different patients. The amount of sulphur remaining 'fixed' after drying the stools, both after iron administration or in melaena stools, is negligible and this is to be expected in view of the relative instability of iron sulphide as compared with bismuth sulphide.

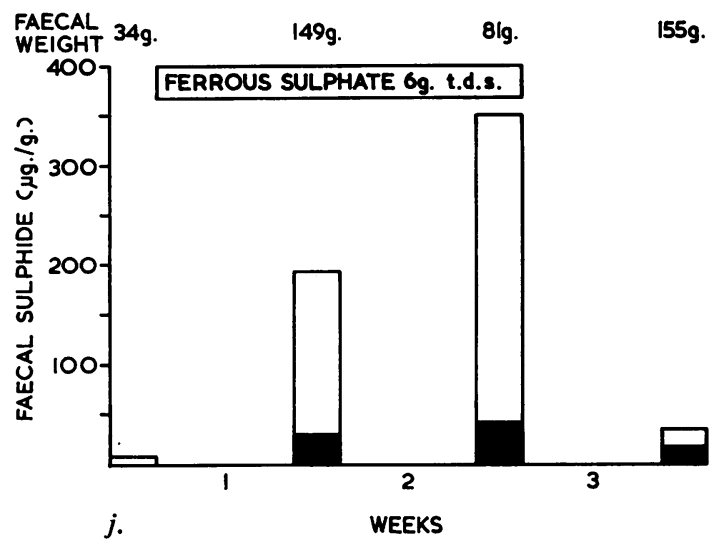

FIG. 6. The effect in a normal subject of administration of ferrous sulphate on faecal sulphide content. Note that stools passed on the same day in each of four weeks were assayed for sulphide, the result being expressed in $\mu g . / g$. faeces (wet weight).

\section{DISCUSSION}

A conclusion arising from this work is that 50 or $60 \mathrm{mg}$. of sulphur, perhaps as much as $10 \%$ of the dietary sulphur, can appear in inorganic form in the stools during bismuth therapy. Certainly this is true of short-term bismuth administration, although it seems likely that the sulphur content of the stools decreases with continued administration. The immediate diminution in faecal sulphide, which results 
from sterilization of the bowel with Neomycin, suggests that the sulphide results from bacterial decomposition of protein; bismuth salts have some bacteriostatic effect which may also explain why faecal sulphide concentration diminishes with continued therapy.

The catabolism of sulphur-containing substances within the body results mainly in sulphates and thiosulphates which are excreted in the urine. It seems likely, however, that hydrogen sulphide is a major end product of bacterial decomposition of such substances within the lumen of the gut; indeed in experimental obstruction of the small intestine in dogs (Hibbard, 1936) hydrogen sulphide comprised between 1 and $10 \%$ of the gas evolved in obstructed loops. Under normal conditions the small intestine contains very little gas, although large quantities may accumulate in the colon. Analysis of human colonic flatus (Fries, 1906; Kirk, 1949) reveals little or no hydrogen sulphide; possibly this is because most collections of such gas have been made over water, but the low concentration of hydrogen sulphide in flatus is in any event not surprising owing to the high solubility and diffusibility of the gas (Andersen and Ringsted, 1943).

If we assume from the data presented in this work that say $50 \mathrm{mg}$. of hydrogen sulphide may be produced in the gut in 24 hours we must also conclude that the body normally has a formidable defence against this most poisonous gas. Claude Bernard (1856) demonstrated in dogs the relative innocuity of rectal administration of quite large volumes of hydrogen sulphide and showed that lead acetate papers held under the dog's nose could become blackened within a few minutes; in recent times hydrogen sulphide has been detected in the breath of patients with Wilson's disease when treated with potassium sulphide. Normally, inorganic sulphide reaching the liver is converted to thiosulphate (Sörbo, 1958), but it seems likely that most of the hydrogen sulphide produced in the gut is inactivated within the gut wall. Before inactivation, however, hydrogen sulphide presumably has an irritant effect on the gut and this is likely to be the basis for the laxative action of the older sulphur-containing purgatives. We do not know to what extent hydrogen sulphide produced by bacterial decomposition of gut contents has a physiological role in promoting peristalsis, but it is a reasonable assumption that removal of hydrogen sulphide by bismuth must have a sedative effect on the gut. Colonic function is frequently disturbed in peptic ulcer patients and this may contribute greatly to abdominal discomfort; it is likely, therefore, that bismuth salts add to the comfort of these patients by fixing hydrogen sulphide and thus lessening colonic irritability.
SUMMARY

A method for measuring the inorganic sulphur content of faeces is described.

The normal daily inorganic sulphur content of faeces is of the order 0.5 to $2 \mathrm{mg}$.

Single doses of bismuth carbonate in two subjects were followed next day by a faecal sulphide output of 7 and $13 \mathrm{mg}$. Continued administration of bismuth carbonate $(3 \mathrm{~g}$. daily) in three subjects caused temporary rises in faecal sulphide to from 40 to $65 \mathrm{mg}$. daily. Ten-fold increase in the dose of bismuth carbonate did not further increase faecal sulphide. In two subjects on bismuth the faecal sulphide fell rapidly to normal when Neomycin was also administered.

Administration of magnesium, aluminium, and calcium salts does not increase inorganic faecal sulphide. Iron salts cause an increase in total faecal sulphide of the same order as bismuth salts, but the 'fixed' proportion is much less.

\section{APPENDIX}

METHOD

Freshly passed stools were transferred from bed pan or commode to screw-cap glass jars and kept in a refrigerator until sulphur estimations were made (normally within 24 hours).

The stools were weighed before being conveyed to a food mixer when they were emulsified with $250-750 \mathrm{ml}$. ice-cold distilled water, according to bulk.

Samples, each of $1 \mathrm{ml}$., of the emulsified stool were distributed in each of four small weighed tubes of approximately $8 \mathrm{ml}$. capacity. Two of these tubes each contained $1 \mathrm{ml}$. iced water, the other two, $1 \mathrm{ml}$. each of $5 \%$ cadmium acetate solution. The tubes were placed in a beaker under an infra-red filament lamp overnight and when thoroughly dry next morning they were re-weighed. The mean deviation regarding the weight of faeces deposited in each pair of tubes was small, being $2.3 \pm 0.43 \%$ in a series of 69 duplicate estimations.

The inorganic sulphide content of each tube was measured by a modification of the method of Karges and Lang (1955).

CHEMICALS The following reagents were made up. Cadmium acetate (Analar) $5 \%$ solution in distilled water.

Ferric ammonium sulphate solution Solution made by adding $5 \mathrm{ml}$. concentrated sulphuric acid to $25 \mathrm{~g}$. ferric ammonium sulphate and making up to $200 \mathrm{ml}$. with distilled water.

Dimethyl paraphenylene diamine of this substance, $0.5 \mathrm{~g}$. was added to a cooled mixture of $200 \mathrm{ml}$. concentrated sulphuric acid in about $500 \mathrm{ml}$. distilled water. Total volume then made up to $1,000 \mathrm{ml}$. 


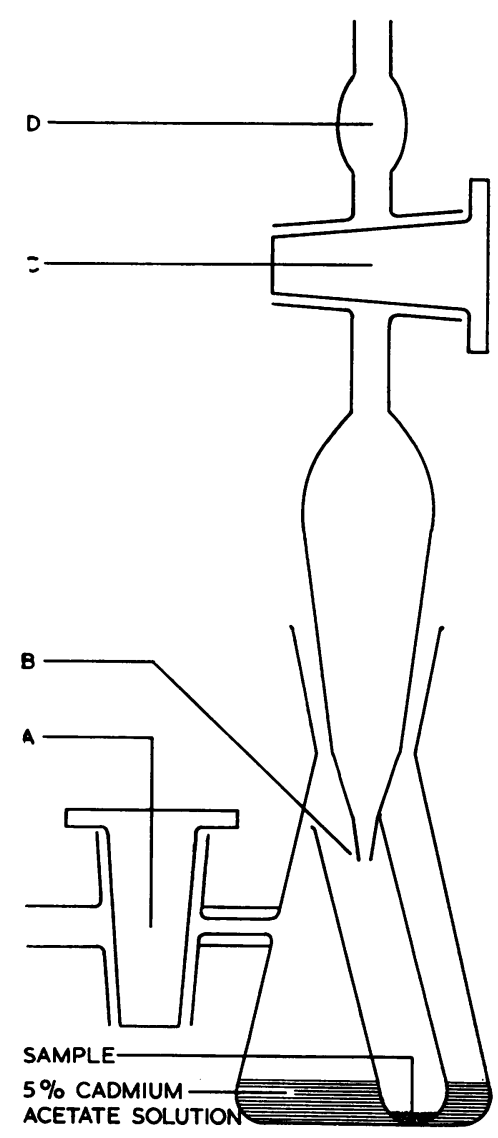

APPARATUS The apparatus is shown in the diagram.

Four $100 \mathrm{ml}$. Quickfit conical flasks equipped with side arm and tap (a). Each flask closed by a hollow ground glass stopper drawn out to a blunt point (b) about $2 \mathrm{~cm}$. below the neck of the flask, and above the neck of the flask a tap (c) surmounted by a small reservoir (d) of approximately $2 \mathrm{ml}$. capacity. All joints lubricated with silicone.

CHEMICAL PROCEDURE Each of the four small tubes containing the dried faecal sample with or without added cadmium acetate were placed in each of the four flasks, all of which contained $5 \mathrm{ml} .5 \%$ cadmium acetate solution. In each case the flask was closed with the hollow stopper dipping just inside the mouth of the small test tube. After air was expelled from the flask by a current of nitrogen, $2 \mathrm{ml}$. of concentrated $\mathrm{HCl}$ was allowed to run throught the hollow stopper in to the small test tube and both the inlet and outlet taps closed immediately.

All four flasks were put on an automatic shaker. The speed of the agitation was adjusted so that the contents of the small tubes were adequately mixed without spill over of fluid in to the cadmium acetate solution in the base of the flask.
After three hours of continuous shaking the flasks were disconnected and stoppers removed. No attempt was made to remove the small tubes. Occasionally, an odour of hydrogen sulphide indicated that not all the gas evolved from the faecal sample had been absorbed by the cadmium acetate. In such cases the whole procedure was repeated.

One millilitre of the ferric ammonium sulphate solution was added to the contents of the flask and then with each flask tilted so as to present the minimum surface area of its liquid contents to the atmosphere, $5 \mathrm{ml}$. of the paraphenelene diamine dye solution was slowly and carefully run under the cadmium acetateferric ammonium sulphate mixture. The flask was quickly closed by an ordinary ground glass stopper and gently agitated for a further hour while the hydrogen sulphide liberated from the cadmium sulphide was taken up by the dye solution to form methylene blue according to the equation:-

$$
\begin{aligned}
& \left(\mathrm{CH}_{3}\right)_{2} \mathrm{NC}_{6} \mathrm{H}_{4} \mathrm{NH}_{2}+\mathrm{NH}_{2} \cdot \mathrm{C}_{6} \mathrm{H}_{4} \cdot \mathrm{N}\left(\mathrm{CH}_{3}\right)_{2}+\mathrm{H}_{2} \mathrm{~S} \\
& \left(\mathrm{CH}_{3}\right)_{2} \mathrm{NC}_{6} \mathrm{H}_{3} \mathrm{C}_{6} \mathrm{H}_{3} \cdot \mathrm{N} \cdot\left(\mathrm{CH}_{3}\right)_{2}+\mathrm{NH}_{3}
\end{aligned}
$$

The intensity of the blue colour was read at the end of an hour on a Hilger photoelectric colorimeter. The colour is stable for at least 24 hours and there is a linear relationship between its absorption at $700 \mu \mathrm{u}$. and the amount of hydrogen sulphide liberated from the cadmium.

The sulphur content was read off from calibration curves prepared by putting iodometrically standardized fresh solutions of sodium sulphide through the above procedure.

The reason for adopting this rather involved procedure is that sulphur in firm chemical combination with bismuth can only be fully released by addition of concentrated acids; indeed, when we tried the simpler method of estimating sulphur in freshly emulsified $1 \mathrm{ml}$. aqueous aliquots of stool results were low, owing to the inevitable dilution of the acid.

The inorganic sulphur content of the samples in the tubes containing distilled water only presumably represents sulphur which is in firm chemical combination. These values are usually considerably lower in a given sample of faeces than those obtained when the emulsified sample is mixed with cadmium acetate. The presumption is that as the specimen dries out under the lamp loosely bound hydrogen sulphide is trapped by the cadmium acetate. Results in these samples represents, therefore, the total inorganic sulphide content of the stool sample. Estimations of 'fixed' and total sulphide were carried out in duplicate and in 79 such paired estimations the mean deviation between two samples was $12.2 \pm$ $1.9 \%$. With experience of the techniques these differences decreased. The average between two readings has been taken for the presentation of the results.

We are indebted to the Board of Governors of The London Hospital for facilities with which to carry out this work, and we thank Professor C. J. O. R. Morris 
and Dr. D. Jennings for advice and encouragement, and also the ward sisters at The London Hospital and Whipps Cross Hospital, E.11, for their cooperation in the collection of specimens.

\section{REFERENCES}

Alstead, S. (1954). An assessment of antacids. Practitioner, 172 131-137.

Andersen, K., and Ringsted, A. (1943). Clinical and experimental investigations on ileus with particular reference to the genesis of intestinal gas. Acta chir. scand., 88, 475-502.

Bateson, P. R. (1954). The effect of bismuth carbonate and other antacids on the activity of pepsin. Med. ill. (Lond.), 8, 370-375.

Bernard, C. (1856). Innocuité de l'hydrogène sulfuré introduit dans les voies digestives; cause de cette innocuité démonstrée par l'expérience. C.R. Soc. Biol. (Paris), 2 S., 3, 137-138.
Caley, H. A. (1905). Some points in the action and uses of bismuth salts. Trans. ther. Soc. (Lond.), 3, 76-84.

Doll, R., Jones, F. Avery, and Buckatzsch, M. M. (1951). Incidence of peptic ulcer. Spec. Rep. Ser, med. Res. Coun. (Lond.), 276, 29.

Druitt, R. (1862). On the use and dose of bismuth. Med. Tms (Lond.), $2,598$.

Fries, J. A. (1906). Intestinal gases of man. Amer. J. Physiol., 16, 468-474.

Hibbard, J. S. (1936). Gaseous distension associated with mechanical obstruction of the intestine. Arch. Surg., 33, 146-167.

Karges, O., and Lang, K. (1955). Zur Methodik der Schwefelwasserstoff-bestimmung in biologischen Material. Klin. Wschr., 33, 825-826.

Kirk, E. (1949). The quantity and quality of human colonic flatus. Gastroenterology, 12, 782-794.

Sörbo, B. (1958). On the formation of thiosulfate from inorganic sulfide by liver tissue and heme compounds. Biochim. biophys. Acta (Amst.), 27, 324-329. 